\title{
JPEB
}

Jurnal Penelitian Ekonomi dan Bisnis, 3 (1), 2018, Hal: 12 - 21

http://www.jpeb.dinus.ac.id

\section{MODEL KEBIJAKAN MODAL KERJA PADA UMKM DI DESA WISATA "CENGEK" TINGKIR LOR, SALATIGA}

\author{
Lenni Yovita $^{1 *}$, Bara Zaretta ${ }^{2}$ dan Vinko Satrio Pekerti ${ }^{3}$ \\ $1,2,3$ \\ Program Studi Manajemen, Universitas Dian Nuswantoro Semarang \\ Jalan Nakula I No. 5-11 Semarang, Indonesia \\ *Corresponding Author : lenniyovita@email.com
}

Diterima: November 2017; Direvisi: Januari 2018; Dipublikasikan: Maret 2018

\begin{abstract}
This study aims to know a model of working capital policy used by Micro, Small and Medium Enterprises (SMEs) in Tourism Village "Cengek" Tingkir Lor, Salatiga. The research method of this study used descriptivequantitative analysis and sampling technique by observation and interview. Sample selection method used is purposive sampling with a sample of 20 SMEs. The results showed that 70\% of SMEs entrepreneurs in Tourism Village "Cengek" Tingkir Lor, Salatiga use a moderate working capital policy, 15\% use conservative working capital policy and the remaining 15\% use aggressive policy. The suggestions are (1) SMEs entrepreneurs begin to bring investors as financiers with agreed business calculations (2) SME entrepreneurs which use conservative working capital policies should dare to use external funds
\end{abstract}

Keywords : Working Capital Policy; SMEs

\section{ABSTRAK}

Penelitian ini bertujuan untuk mengetahui model kebijakan modal kerja yang digunakan oleh Usaha Mikro, Kecil dan Menengah (UMKM) di Desa Wisata "Cengek" Tingkir Lor, Salatiga.Metode penelitian dalam penelitian ini menggunakan analisis deskriptif kuantitatif dan teknik pengambilan sampel dengan observasi dan wawancara. Metode pemilihan sampel yang digunakan adalah purposive sampling dengan sampel sebanyak 20 UMKM. Hasil penelitian menunjukkan bahwa $70 \%$ pengusaha UKM di Desa Wisata "Cengek" Tingkir Lor, Salatiga menggunakan kebijakan modal kerja yang moderat, 15\% menggunakan kebijakan modal kerja konservatif dan sisanya 15\% menggunakan kebijakan agresif. Rekomendasi dari hasil penelitian ini adalah (1) pengusaha UKM mulai membawa investor sebagai pemodal dengan perhitungan bisnis yang disepakati (2) pengusaha UKM yang menggunakan kebijakan modal kerja konservatif harus berani menggunakan dana eksternal

Kata Kunci : Kebijakan Modal Kerja; UMKM 



\section{PENDAHULUAN}

Modal kerja adalah faktor fundamental dalam aktivitas operasional sebuah usaha. Ibarat pelumas mesin, begitupun modal kerja mempunyai fungsi yang sama, yaitu memperlancar keberlangsungan usaha. Modal kerja juga merupakan dana yang diperlukan untuk memenuhi kebutuhan operasional perusahaan sehari-hari (Riyanto, 2013). Modal kerja dialokasikan untuk membeli bahan baku, membayar gaji karyawan, mengeluarkan biayabiaya yang diperlukan, dan lain sebagainya perlu diatur. Pada umumnya ia akan bersiklus dalam periode tertentu, dan diharapkan akan menuai hasil yang lebih daripada modal kerja awal.

Perencanaan dan pengelolaan modal kerja tentu harus bijak dan tepat sesuai sasaran sehingga memudahkan operasionalisasi usaha dan berpotensi terhindar dari pailit sehingga memerlukan kebijakan modal kerja yang sesuai. Tiga konsep kebijakan modal kerja (Riyantor, 2013) yaitu kuantitatif, kualitatif dan fungsional. Letak perbedaan paling menonjol adalah pada besaran prosentasi penggunaan aktiva lancar. Sedangkan tipe kebijakan modal kerja berdasarkan pengembangan konsep kebijakan modal kerja adalah konservatif, moderat (hedging), dan agresif (Weston dan Copeland, 2012). Skala perusahaan mulai dari Usaha Mikro, Kecil, Menengah (UMKM) hingga usaha berskala besar memerlukan kebijakan modal kerja yang efesien dan taktis.

UMKM mulai berkembang pesat pada lima tahun terakhir. Tercatat bahwa UMKM memberikan kontribusi positif terhadap Produk Domestik Bruto (PDB) dari 57, 84\% (2011) meningkat menjadi 60, 34\% (2016). UMKM juga menunjukkan prestasinya dalam penyerapan tenaga kerja, yaitu dari 96, 99\% meningkat hingga 97,22\% dalam kurun waktu lima tahun terakhir (BPS, 2016). Rekam jejak UMKM yang baik harus mendapatkan perhatian pemerintah. Walaupun bukan usaha berskala nasional bahkan multinasional, akan tetapi UMKM terbukti menjadi kontributor signifikan dalam peningkatan Produk Domestik Bruto. Hal tersebut juga selaras dengan penelitian Tambunan (2011) yang menyatakan bahwa selain sebagai sumber ketenagakerjaan, usaha skala kecil hingga menengah (Small to Medium Enteprises) berpotensi sebagai mesin pertumbuhan ekonomi dalam negeri. Ironisnya, UMKM mempunyai beberapa kendala dalam operasionalisasi usaha, yaitu kesulitan pemasaran dan bahan baku, keterbatasan - keterbatasan dalam hal akses ke sumber pembiayaan sumber daya manusia (SDM), inovasi dan teknologi (Roeslani, 2016)

Salatiga merupakan kota kecil yang sejuk, berlokasi di kaki gunung Merbabu Jawa Tengah serta secara administrasi terletak diantara kabupaten Semarang dan Boyolali. Salah satu desa di Salatiga yaitu Desa Tingkir Lor telah ditetapkan dengan SK Walikota Nomor : 556/349/2015 sebagai lokasi pengembangan Desa Wisata. UMKM tumbuh pesat seiring dengan perkembangan Desa Wisata.

Hasil produksi yang dihasilkan Desa Tingkir Lor (Cengek) bervariasi. Produk yang dihasilkan berupa pakaian pakai seperti baju, celana, jaket, kaos, dan atribut muslim seperti kerudung. Produk lain yang dihasilkan adalah sprei, sarung bantal dan guling, selimut yang berbahan dasar macam - macam kain. Sebagian besar industri di desa ini bergerak di bidang konveksi. Akan tetapi, terdapat pula usaha lainnya yaitu kuliner seperti: bakpia, keripik, dan krecek. Adapula beberapa industri rumah tangga yang menjadi pengrajin tempe. Sebagian kecil lainnya menjadi ternak ikan serta pengrajin alat rumah tangga seperti sapu, kemoceng, sikat dan sebagainya.

Mayoritas pelaku UMKM di Desa Wisata Cengek menerapkan konsep dan tipe kebijakan modal kerja kuantitatif - konservatif.Hal ini disebabkan adanya tingkat kesulitan untuk memperoleh pembiayaan dari kreditur, yaitu perbankan sehingga terkendala dalam pengembangan usaha.Hal ini juga sejalan dengan hasil penelitian Sunday (2011) dan Tambunan (2011) yang menyatakan bahwa perusahaan kecil mengalami kesulitan finansial karena tidak memenuhi persyaratan pemberian kredit oleh perbankan.75\% pelaku UMKM di 
desa tersebut menggunakan aktiva lancar yang bersumber dari modal internal. Sehingga aspek tujuan studi ini adalah untuk mengetahui modal kerja pada UMKM di Desa Wisata Cengek,Salatiga dan selanjutnya memberikan rekomendasi dari hasil studi ini.

Penelitian ini bermanfaat bagi masyarakat pada umumnya dan secara khusus bagi UMKM di Desa Cengek, Salatiga sebagai bentuk pembelajaran dan wacana tentang kebijakan modal kerja. Begitu juga dalam dunia pendidikan,bahwa hasil penelitian ini bermanfaat sebagai bahan ajar.

\section{TINJAUAN PUSTAKA}

\section{Modal Kerja}

Tiga konsep modal kerja (Riyanto, 2013), antara lain :

1. Kuantitatif

Modal kerja terdiri dari seluruh jumlah aktiva lancar.Konsep ini biasa disebut modal kerja bruto (gross working capital). Modal kerja konsep kuantitatif hanya menekankan aspek ketersediaan dana jangka pendek untuk operasional usaha rutin.

2. Kualitatif

Modal kerja konsep kualitatif lebih luas cakupannya karena sudah memasukkan elemen hutang lancar.Sebagian aktiva lancar harus bisa mendanai seluruh aktivitas operasional rutin perusahaan, sedangkan sebagian sisanya digunakan untuk membayar hutang lancar.

3. Fungsional

Modal kerja konsep fungsional menekankan fungsi dana dalam memproduksi pendapatan. Tidak semua dana akan dihabiskan dalam periode sekarang akan tetapi ada kemungkinan akan digunakan untuk periode yang akan datang.

Setiap usaha berbeda-beda dalam menentukan Model atau tipe kebijakan modal kerja.Penentuan tersebut disesuaikan dengan karakter, skala, visi misi dan jenis usaha.Menurut Weston dan Copeland (2012), terdapat 3 (tiga) tipe atau Model kebijakan modal kerja, yaitu:

1. Kebijakan Konservatif

Pada kebijakan Model konservatif, penetapan tingkat aktiva lancar yang relatif tinggi mengakibatkan likuiditas perusahaan tinggi. Implikasi selanjutnya adalah terjadi resiko kekurangan persediaan atau kehilangan kesempatan penjualan yang rendah akan tetapi profitabilitas rendah.

2. Kebijakan Moderat

Kebijakan Model moderat (hedging) merupakan perpaduan diantara dua kebijakan sebelumnya. Penetapan tingkat aktiva lancar rata - rata yang relatif cukup mengakibatkan likuiditas pada level moderat alias sedang. Implikasi selanjutnya adalah terjadi tingkat penjualan yang moderat dan profitabilitas perusahaan sedang.

3. Kebijakan Agresif

Pada kebijakan Model agresif, penetapan tingkat aktiva lancar rata - rata yang relatif rendah mengakibatkan likuiditas rendah. Implikasi selanjutnya adalah terjadi resiko kekurangan persediaan atau kehilangan kesempatan penjualan tinggi sehingga profitabilitas perusahaan tinggi. Tabel 1 dibawah ini merupakan ringkasan Model atau tipe kebijakan modal kerja : 
Tabel 1. Tingkat Likuiditas, Profitabilitas, dan Risiko pada Tiga Kebijakan

\begin{tabular}{llll}
\hline & Tinggi & Sedang & Rendah \\
\hline Likuiditas & Konservatif & Moderat & Agresif \\
Profitabilitas & Agresif & Moderat & Konservatif \\
Risiko & Agresif & Moderat & Konservatif \\
\hline
\end{tabular}

4 (empat) faktor yang menentukan kebutuhan modal kerja perusahaan (Hampton, 2011), yaitu :

1. Volume Penjualan

Perusahaan membutuhkan modal kerja untuk mendukung potensi peningkatan volume penjualan.

2. Faktor Musim dan Siklus

Fluktuasi dalam penjualan yang disebabkan oleh faktor musim dan siklus akan mempengaruhi kebutuhan akan modal kerja.

3. Perubahan dalam Teknologi

Jika terjadi pengembangan teknologi maka akan berhubungan dengan proses produksi dan akan membawa dampak terhadap kebutuhan akan modal kerja

4. Kebijakan Perusahaan

Kebijakan yang diterapkan oleh perusahaan juga akan membawa dampak terhadap kebutuhan modal kerja.

\section{Penelitian Terdahulu}

Miswanto (2012) melakukan studi literatur tentang kebijakan dalam penentuan dan pendanaan modal kerja. Hasil studinya adalah (1) bilamana aktiva lancar temporer dibiayai dengan pendanaan jangka pendek mengandung resiko dan profitabilitas yang moderat, (2) bilamana aktiva lancar temporer dibiayai dengan pendanaan jangka panjang mengandung resiko dan profitabilitas yang rendah, (3) bilamana aktiva lancar permanen dibiayai dengan pendanaan jangka pendek akan mengandung resiko dan profitabilitas tinggi, (4) bilamana aktiva lancar permanen dibiayai dengan pendanaan jangka panjang akan mengandung resiko dan profitabilitas yang moderat, (5) untuk menganalisis modal kerja bisa digunakan alat analisis rasio keuangan, analisis sumber dan penggunaan dana, dan analisis aliran kas.

Sadiq (2017) menguji pengaruh modal kerja terhadap kinerja Usaha Mikro, Kecil dan Menengah di Nigeria. Hasil pengujian menunjukkan bahwa periode hutang dagang,siklus konversi kas, dan siklus perdagangan bersih berpengaruh posistif terhadap kinerja perusahaan. Periode piutang dagang dan perputaran persediaan dalam satuan hari mempunyai hubungan yang negative dengan kinerja perusahaan.

Sunday (2011) melakukan penelitian yang berjudul Effective Working Capital Management in Small and Medium Scale Enterprises (SMEs). Hasilnya : (1) bahwa perusahaan skala kecil mempunyai kelemahan finansial karena sangat tergantung dengan fasilitas kredit, (2) banyak perusahaan kecil tidak mampu membayar seluruh kewajiban baik jangka pendek maupun jangka panjang (insolvable) dikarenakan kesulitan mendapatkan bantuan keuangan sebab tidak memenuhi persyaratan mendapatkan kredit, (3) aliran modal kerja yang rendah menjadikan perusahaan kecil tidak mampu berkompetisi

Penelitian Tambunan (2011) tentang Development of Small and Medium Enterprises in Developing Country-The Indonesia Case, menunjukkan hasil yaitu (1) UMKM adalah pemain utama dalam menggerakan perekonomian negara karena jumlah mereka hampir 99.9\% dari jumlah keseluruhan perusahaan domestic, (2)UMKM mempunyai kesulitan 
keuangan dan keterbatasan pemasaran, (3) inovasi UMKM sangat rendah, (4). Pengusaha wanita masih sedikit akibat kendala pendidikan, pandangan budaya dan agama.

Sugiyono (2015) melakukan penelitian tentang penggunaan dan penyediaan modal kerja UMKM dalam meningkatkan laba KUB ( Kelompok Usaha Bersama) Alam Lestari Depok. Hasil penelitiannya menujukkan bahwa penyediaan dan penggunaan modal kerja KUB lestari didasarkan pada sifat umum perusahaan, waktu produksi, tingkat perputaran persediaan, tingkat perputaran piutang, dan pengaruh konjungtur

\section{Populasi dan Sampel}

Populasi dalam penelitian ini adalah seluruh UMKM di Desa Wisata, Cengek Salatiga, yaitu 72 UMKM. Peneliti mengambil sampel UMKM di Cengek berdasarkan kriteria kesamaan usaha . Pada Sentra industri konveksi desa wisata Tingkir lor terdapat 5 (lima) jenis spesialisasi konveksi, yaitu : pembuat sprei dan bed cover, celana kolor, hijab, pakaian umum dan campur. Setiap jenis spesialisasi UMKM akan diambil sampel secara proporsional yaitu $20 \%$.

Maka kriteria sampel diatas telah memperoleh sampel sebanyak 20 UMKM dengan rincian sebagai berikut :

\begin{tabular}{|c|c|c|}
\hline \multicolumn{2}{|l|}{ Kriteria } & Jumlah \\
\hline \multicolumn{2}{|c|}{ Seluruh pengusaha UMKM di Tingkir Lor } & 72 \\
\hline \multicolumn{3}{|c|}{ Spesialisasi UMKM : } \\
\hline \multicolumn{2}{|c|}{$\begin{array}{l}\text { a. Sprei dan bed cover : } 16(20 \%) \\
\text { b. Celana kolor } \quad: 21(20 \%)\end{array}$} & 3 \\
\hline \multirow{4}{*}{$\begin{array}{l}\text { c. Hijab } \\
\text { d. Pakaian umum } \\
\text { e. Campur }\end{array}$} & $: 3 \quad(20 \%)$ & 5 \\
\hline & : $20(20 \%)$ & 1 \\
\hline & $: 12(20 \%)$ & 4 \\
\hline & & 3 \\
\hline Total & & 20 \\
\hline
\end{tabular}

Metode pemilihan sampel menggunakan pemilihan sampel bertujuan (purposive sampling) berdasarkan kuota. Metode tersebut bertujuan untuk menaikkan representative sampel penelitian (Indriantoro dan Soepomo, 2011)

\section{Teknik Pengumpulan Data}

Penelitian ini menggunakan data primer sekaligus data sekunder dengan teknik pengumpulan data, yaitu observasi dan wawancara responden yaitu 20 pengusaha UMKM di Desa Wisata Cengek, Salatiga.

\section{Variabel Penelitian}

Variabel penelitian dalam penelitian ini adalah Kebijakan modal kerja. Pada tabel 3.1 berikut ini memaparkan definisi operasional beserta indikator variabel :

Tabel 3. Variabel, Indikator, dan Definisi Operasional Penelitian

\begin{tabular}{|c|c|c|c|}
\hline Variabel & \multicolumn{2}{|c|}{ Indikator } & Definisi Operasional \\
\hline \multirow{3}{*}{$\begin{array}{l}\text { Model } \\
\text { Kebijakan } \\
\text { Modal Kerja }\end{array}$} & $\begin{array}{l}\text { Kelas I } \\
\text { Konservatif }\end{array}$ & $\frac{\text { Aktiva Lancar }}{\text { Penjualan }}$ & $\begin{array}{l}\text { Jumlah aktiva lancar yang relatif besar } \\
\text { mengakibatkan likuiditas tinggi. }\end{array}$ \\
\hline & $\begin{array}{l}\text { Kelas II } \\
\text { Moderat }\end{array}$ & $\frac{\text { Aktiva Lancar }}{\text { Penjualan }}$ & $\begin{array}{l}\text { Jumlah aktiva lancar rata-rata yang relatif cukup } \\
\text { mengakibatkan likuiditas pada level moderat } \\
\text { alias sedang }\end{array}$ \\
\hline & $\begin{array}{l}\text { Kelas III } \\
\text { Agresif }\end{array}$ & $\frac{\text { Aktiva Lancar }}{\text { Penjualan }}$ & $\begin{array}{l}\text { Jumlah aktiva lancar rata-rata yang relatif rendah } \\
\text { mengakibatkan likuiditas rendah }\end{array}$ \\
\hline
\end{tabular}




\section{Teknik Analisis Data}

Teknik analisis data dalam penelitian ini menggunakan perhitungan kuantitatif, yaitu dengan cara dan tahapan sebagai berikut :

1. Membandingkan Aktiva lancar dan penjualan

2. Hasil perbandingan pada butir 1(satu) yang berupa angka absolut dikonversi menjadi prosentase

3. Menyajikan hasil perbandingan atau perhitungan butir 2(dua) ke dalam tabel distribusi frekuensi

4. Membentuk 3 kelas interval pada hasil perhitungan di butir 2 ke dalam 3 kelas kebijakan yang telah dibuat dengan interval kelas atau jangkauan kelas dengan tahapan :

a. Mengurutkan nilai data dari yang terkecil ke terbesar

b. Membuat 3 kelas interval yang disesuaikan dengan 3 kategori kebijakan yaitu Kelas I

- Kebijakan Konservatif, Kelas II - Kebijakan Moderat, Kelas III - Kebijakan Agresif

c. Mencari panjang interval kelas dengan formula : Panjang kelas $(\mathrm{PK})=($ nilai terbesar - nilai terkecil ) / Jumlah kategori

d. Menghitung banyaknya frekuensi per kelas kebijakan modal kerja

5. Tahap selanjutnya adalah membuat kesimpulan dengan dasar perhitungan frekuensi pada butir 5d (lima d) .

\section{HASIL DAN PEMBAHASAN}

\section{Statistik Deskriptif}

Hasil wawancara terhadap 20 pengusaha UMKM konveksi di Desa Wisata, Tingkir Lor Salatiga dan observasi langsung tentang prospektus bisnis telah memunculkan data berikut ini :

\section{Sumber Pendanaan}

Tabel 4. Sumber Pendanaan Pengusaha UMKM di Desa Wisata Tingkir Lor, Salatiga

\begin{tabular}{cccccc}
\hline & Umur Bisnis & $\begin{array}{c}\text { Jumlah } \\
\text { Pengusaha }\end{array}$ & \multicolumn{3}{c}{ Sumber Pendanaan } \\
\cline { 4 - 6 } UMKM & Internal & Eksternal & $\begin{array}{c}\text { Internal dan } \\
\text { Eksternal }\end{array}$ \\
\hline 1 & $<1$ tahun & 2 & 2 & 0 & 0 \\
2 & $1-5$ tahun & 4 & 1 & 0 & 3 \\
3 & $>5$ tahun & 14 & 0 & 0 & 14 \\
\hline & Total & 20 & 3 & 0 & 17 \\
\hline
\end{tabular}

Berdasarkan tabel 3 diatas, menunjukkan bahwa pengusaha UMKM yang mempunyai umur bisnis kurang dari 1 (satu ) tahun belum mempunyai keberanian untuk menggunakan dana eksternal, yaitu kredit dari perbankan.

Lain halnya dengan para pengusaha UMKM yang mempunyai umur bisnis lebih dari 1(satu) tahun lebih mempunyai keberanian menggunakan sumber pendanaan eksternal. Hal tersebut dikarenakan rata-rata pengusaha UMKM tersebut sudah mempunyai gambaran bisnis ke depan mereka. Selain itu, pengalaman berbisnis konveksi lebih dari satu tahun menjadikan mereka lebih percaya diri dalam mengelola dana kucuran perbankan. Seperti yang diungkapkan Mariyani (50 tahun). Ibu dari 2 putra ini sudah menjalankan usaha konveksi selama 20 tahun. Ibu Mariyani sering memadukan sumber pendanaan baik internal maupun eksternal. Histori bisnis Ibu Mariyani telah memotret tren bisnis yang dijalankan semakin mempunyai kapasitas besar. Awal berdiri usahanya hanya memproduksi bahan kain kiloan hanya satu kilo hingga ratusan kilo dan telah mempunyai 3 outlet di Salatiga. Menurutnya, dukungan perbankan menjadi salah satu faktor kesuksesan usahanya. 
Lenni Yovita, Bara Zaretta dan Vinko Satrio Pekerti: Model Kebijakan Modal Kerja Pada UMKM Di Desa Wisata "Cengek" Tingkir Lor, Salatiga

Tinjauan secara keseluruhan bahwa17 (85\%) dari 20 responden menggunakan perpaduan sumber pendanaan, yaitu internal dan eksternal. Hal tersebut menunjukkan bahwa pengusaha UMKM di Desa Wisata, Tingkir Salatiga mempunyai sistem pengelolaan keuangan yang baik dan tren bisnis yang menjanjikan. Mereka berharap bahwa usaha mereka akan terus berkelanjutan hingga anak cucu.

\section{Prospektus Bisnis}

Tabel 5. Ringkasan Prospektus Bisnis Pengusaha UMKM di Desa Wisata Tingkir Lor, Salatiga

\begin{tabular}{cllll}
\hline No & $\begin{array}{l}\text { Umur } \\
\text { Bisnis }\end{array}$ & Penjualan kotor & Aset Lancar & Hutang Lancar \\
\hline \multirow{2}{*}{1} & $<1$ tahun & $20.000 .000-60.000 .0000$ & $40.000 .000-$ & 0 \\
& & & 80.000 .000 & \\
2 & \multirow{2}{*}{$1-5$ tahun } & $60.000 .000-150.000 .000$ & $50.000 .000-$ & $30.000 .000-$ \\
& & & 200.000 .000 & 200.000 .000 \\
3 & $>5$ tahun & \multirow{2}{*}{$150.000 .000-1.500 .000 .000$} & $120.000 .000-$ & $100.000 .000-$ \\
& & & & \\
\hline
\end{tabular}

Tabel 4 tentang ringkasan prospektus bisnis pengusaha UMKM di Desa Wisata, Tingkir Lor, Salatiga menunjukkan bahwa semakin lama umur bisnis UMKM, maka skala perusahaan makin besar. Hal tersebut diindikasikan dengan peningkatan penjualan kotor, Aset Lancar, dan Hutang Lancar. Secara keseluruhan, bisnis konveksi di Desa Wisata Tingkir Lor, Salatiga mempunyai prospek bisnis yang positif.

\section{Ekonomi Berbagi (Sharing Economy)}

Para pengusaha UMKM di Desa Wisata, Tingkir Lor Salatiga juga melakukan ekonomi berbagi (sharing economy) bagi masyarakat setempat. Mereka melibatkan beberapa rumah tangga untuk melakukan tahapan kegiatan produksi konveksi, seperti : menjahit, mengobras, dan merapikan jahitan. Karyawan UMKM 100\% berasal dari masyarakat setempat. Berikut ini adalah tabel yang menyajikan ekonomi berbagi (sharing economy) pada 20 pengusaha UMKM di Desa Wisata, Tingkir Lor, Salatiga dari tahun 2016 hingga April 2018 dengan indikator jumlah karyawan.

Tabel 6. Ekonomi Berbagi di Desa Tingkir Lor Salatiga

\begin{tabular}{cccccc}
\hline \multirow{2}{*}{ Tahun } & \multicolumn{3}{c}{ Produksi } & \multicolumn{2}{c}{ Penjualan dan Pemasaran } \\
\cline { 2 - 6 } & Menjahit & Mengobras & $\begin{array}{c}\text { Merapikan } \\
\text { Jahitan }\end{array}$ & $\begin{array}{c}\text { Tenaga Penjualan } \\
\text { dan Pemasaran }\end{array}$ & $\begin{array}{c}\text { Tenaga } \\
\text { Administrasi }\end{array}$ \\
\hline 2016 & 102 & 127 & 195 & 85 & 40 \\
2017 & 104 & 130 & 198 & 86 & 41 \\
2018 & 109 & 135 & 200 & 86 & 41 \\
\hline
\end{tabular}

Tabel 5 diatas menunjukkan bahwa keterlibatan penduduk setempat dalam pengelolaan industri konveksi UMKM di Tingkir lor dari tahun ke tahun makin besar. Hal itu menjadi bukti bahwa usaha konveksi makin berkembang dan ada peningkatan kesejahteraan masyarakat desa Tingkir lor.

Tahap selanjutnya adalah membandingkan aktiva lancar dengan penjualan bruto agar dapat diketahui kebijakan modal kerja yang digunakan, yaitu konservatif, agresif, atau moderat. Berikut ini perhitungan penentuan kebijakan modal kerja pada pengusaha UMKM di Desa Wisata, Salatiga : 
Tabel 7. Perbandingan Aktiva Lancar dengan Penjualan

\begin{tabular}{rlrrcr}
\hline No & $\begin{array}{c}\text { Pengusaha } \\
\text { UMKM }\end{array}$ & \multicolumn{1}{c}{$\begin{array}{c}\text { Aktiva } \\
\text { Lancar }\end{array}$} & $\begin{array}{c}\text { Penjualan } \\
\text { bruto }\end{array}$ & $\begin{array}{c}\text { Perbandingan } \\
\text { Aktiva Lancar dan } \\
\text { Penjualan bruto }\end{array}$ & \% \\
\hline 1 & Ainul Mardiyah & 600.000 .000 & 520.850 .000 & 1,15 & 115,20 \\
2 & Adib Mutofa & 320.000 .000 & 260.000 .000 & 1,23 & 123,08 \\
3 & Amin Sholikah & 720.000 .000 & 530.000 .000 & 1,36 & 135,85 \\
4 & Edi Susilo & 35.000 .000 & 60.000 .000 & 0,58 & 58,33 \\
5 & Khaeroni & 100.000 .000 & 97.000 .000 & 1,03 & 103,09 \\
6 & Ida Magsum & 170.000 .000 & 189.000 .000 & 0,90 & 89,95 \\
7 & Isa & 240.000 .000 & 250.000 .000 & 0,96 & 96,00 \\
8 & Munasikah & 265.250 .000 & 270.000 .000 & 0,98 & 98,24 \\
9 & Mahfiah Rohmah & 93.000 .000 & 90.000 .000 & 1,03 & 103,33 \\
10 & Maksum Afandi & 120.500 .000 & 130.000 .000 & 0,93 & 92,69 \\
11 & Maf'ah & 130.200 .000 & 152.000 .000 & 0,86 & 85,66 \\
12 & Munayiroh & 710.000 .000 & 700.000 .000 & 1,01 & 101,43 \\
13 & Mut Khasanah & 200.800 .000 & 220.000 .000 & 0,91 & 91,27 \\
14 & Mariyani & 147.800 .000 & 163.400 .000 & 0,90 & 90,45 \\
15 & Nur Abidin & 231.000 .500 & 253.700 .000 & 0,91 & 91,05 \\
16 & Nuraini & 272.300 .000 & 251.000 .000 & 1,08 & 108,49 \\
17 & Numan Suntoro & 200.300 .000 & 205.200 .000 & 0,98 & 97,61 \\
18 & Nurhadi & 889.000 .000 & 1.200 .000 .000 & 0,74 & 74,08 \\
19 & Ning Darmaji & 672.000 .000 & 1.000 .000 .000 & 0,67 & 67,20 \\
20 & Swastika & 64.000 .000 & 60.000 .000 & 1,07 & 106,67 \\
\hline
\end{tabular}

Dari tabel 6 diatas maka dapat diperoleh tiga kelas interval dalam distribusi frekuensi sebagai berikut :

Panjang kelas $(\mathrm{PK})=($ nilai datum terbesar - nilai datumterkecil $) /$ Jumlah kategori

$=(135,85-58,33) / 3$

$=25,84$

Tabel 8. Distribusi Frekuensi Perbandingan antara Aktiva Lancar dengan Penjualan

\begin{tabular}{cccc}
\hline Kelas & $\begin{array}{c}\text { Nilai prosentase perbandingan Aktiva } \\
\text { Lancar dengan Penjualan }\end{array}$ & Frekuensi & Prosentase \\
\hline I & $58,00-84,00$ & 3 & $15 \%$ \\
II & $85,00-111,00$ & 14 & $70 \%$ \\
III & $112,00-138,00$ & 3 & $15 \%$ \\
\hline & Total & 20 & $100 \%$ \\
\hline
\end{tabular}

Dari tabel distribusi frekuensi perbandingan aktiva lancar dengan penjualan bruto diatas, dapat diketahui bahwa 15\% pengusaha UMKM di Desa Wisata, Cengek atau Tingkir Lor, Salatiga mengunakan kebijakan modal kerja konservatif. Pengusaha UMKM tersebut memilih komposisi Aktiva Lancar lebih banyak dari hutang lancar karena sesuai profil resiko pengusaha tersebut yaitu takut mengambil resiko (risk averse). Seperti pengungkapan Ibu Swastika (30 tahun) yang merupakan salah satu pengusaha UMKM di Tingkir Lor bahwa sebelum memiliki omset bernilai Milyaran, Swastika tetap berkomitmen menggunakan dana 
internal. Menurutnya, hutang pada pihak ke-3 terlalu beresiko karena ada keterikatan untuk menyediakan dana cicilan sementara bisnis rentan dengan ketidakpastian dan bunga bank belum kompetitif jika dibandingkan dengan perolehan margin kotor per barang.

Sementara 70\% pengusaha UMKM menggunakan kebijakan modal kerja moderat. Pengusaha UMKM tersebut mempunyai keberanian memadukan sumber pendanaan internal dan eksternal karena memiliki pengalaman mengelola bisnis lebih dari 3 tahun. Sejauh pengalaman mereka, pasar merespon positif eksistensi usaha konveksi yang sudah mereka jalankan. Probabilitas kepastian bisnis menguntungkan lebih besar jika ditinjau dari perputaran Aktiva lancar menjadi penjualan hingga menghasilkan laba dan kembali menjadi Aktiva lancar kembali.

15\% dari 20 responden telah menggunakan kebijakan modal kerja agresif. Pengusaha UMKM ini berani mengambil resiko (risk taker). Menurut Amin, bahwa resiko yang tinggi akan menghasilkan keuntungan yang tinggi pula. Amin banyak menggunakan dana eksternal karena sejauh ini usahanya berhasil. Dukungan pihak perbankan menjadikan usahanya lebih berkembang.

Hasil penelitian ini mendukung penelitian Sunday (2011), Tambunan (2011) dan Roeslani (2016) yaitu bahwa perusahaan skala kecil mempunyai kelemahan finansial karena sangat tergantung dengan fasilitas kredit.

\section{SIMPULAN}

Berdasarkan hasil pengolahan data dan analisis, telah didapat kesimpulan bahwa 70\% dari 20 responden lebih banyak menggunakan kebijakan modal kerja moderat. Sedangkan sisanya $15 \%$ lebih memilih konservatif dan $15 \%$ memilih agresif. Hal tersebut sesuai dengan profil resiko pengusaha dan prospek bisnis yang dijalankan.

Peneliti merekomendasikan bahwa pengusaha UMKM yang menggunakan kebijakan modal kerja konservatif harus berani menggunakan dana eksternal dengan pengelolaan yang tepat sasaran. Penggunaan dana eksternal akan membantu pengembangan usaha. Hal tersebut dibuktikan dengan para pengusaha UMKM yang menggunakan dana eksternal ternyata mempunyai perkembangan bisnis yang baik dan lebih ekspansif

\section{DAFTAR PUSTAKA}

Brigham, Eugene F and Daves, Phillip R. 2013. Intermediate Financial Management. $12^{\text {th }}$ Ed. Thomson ONE

Brigham,Eugene $\mathrm{F}$ and Houston, Joel F.2014. Fundamentals of Financial Management.Concise $8^{\text {th }} \mathrm{Ed}$. Thomson ONE

Horne, James C. Van and John M. Wachowicz, Jr. 2001. Fundamental of Financial Management.13Ed. Singapore: PrenticeHall

Husnan, Suad dan Pudjiastuti, Enny. 2006. Dasar-Dasar Manajemen Keuangan. Yogyakarta: UPP AMP YKPN

Indriantoro,Nur dan Supomo, Bambang. 2011. Metodologi Penelitian Bisnis Untuk Akuntansi dan Manajemen. Yogyakarta: BPFE

Kriteria Usaha Mikro, Kecil dan Menengah (UMKM). http://galeriUMKM.web.id/news/kriteria-usaha-mikro-kecil-dan-menengah-umkm. Diakses, tanggal 10 Desember 2017

Miswanto. 2012. Kebijakan Dalam Penentuan dan Pendanaan Modal Kerja Perusahaan. Jurnal Economia. 8(2).

Riyanto, Bambang. 2013. Dasar-dasar Pembelanjaan Perusahaan. Ed.4,Yogyakarta:BPFE

Sadiq,Raji. 2017. Impact of Working Capital Management on Small and Medium Enterprises' Performance in Nigeria. Arabian Journal of Business and Management Review.7:285 
Sunday,James Kehinde. 2011. Effective Working Capital Management in Small and Medium Scale Enterprises (SMEs). International Journal Of Business and Management. 6 (9).

Sudjana. 2011. Metode Statistika. Ed.6. Bandung: Bandung.Tarsito

Tambunan, T.T. Hamonangan. 2011. Development of Small and Medium Enterprises in Developing Country-The Indonesia Case. Journal of Enterprising Communities. 5(1)

Tandelilin, Eduardus. 2010. Portofolio dan Investasi Teori dan Aplikasi, Edisi Pertama, Yogyakarta: Kanisius IKAPI

Undang-Undang Republik Indonesia Nomor 20 Tahun 2008 TentangUsaha Mikro, Kecil, DanMenengah.http://webcache.googleusercontent.com/search?q=cache:htcB9zWRTPg J:www.bi.go.id/NR/rdonlyres/C7402D01-A030-454A-BC759858774DF852/17681/UU20Tahun2008UMKM.pdf+\&cd=1\&hl=en\&ct=clnk. Di akses , tanggal 04 Januari 2018

Zulhaq, Arifah dan Handayani, Nur. 2017. Pengaruh Modal Kerja dan Kebijakan Pendanaan Terhadap Profitabilitas Perusahaan Farmasi. Jurnal Ilmu dan Riset Akuntansi. 6 (1) 